se quer é que seja consagrado pelo Direito, para que seja norma legal. E' contabilidade, mas é Direito, também. E' Direito Financeiro na técnica e cria normas coativas.

O SR. JOSÉ BATISTA NETO - Apenas o autor da tese se portou com mais maestria, por isso que é altamente versado no assunto, e reúne as duas qualidades, é jurista e é contabilista. Entrou com mais profundidade no assunto.

O SR. PRESIDENTE - Vou pôr em votação a proposição da Comissão. Os srs. congressistas que a aprovam, queiram ficar sentados. (Pausa) Aprovada.

\section{BÔLSAS DE VALORES MOBILIÁRIOS - ESTRUTURA E NATUREZA JURÍDICA}

\author{
José Batista Neto \\ Advogado em Pôrto Alegre.
}

(Consultor Jurídico da Bôlsa de Fundos Públicos de Pôrto Alegre).

$$
-\mathrm{I}-
$$

1 - As Bôlsas de Valores são mercados organizados que, pela concentração da oferta e da procura dos títulos da dívida pública, dos emitidos pelas sociedades por ações (ações, debêntures, letras hipotecárias, partes beneficiárias), do câmbio e de outros valores mobiliários, bem como pela disciplina e registro das respectivas operações, facilitam extremamente a circulação dêsses valores, regulam as. suas cotações e dão grande segurạça aos negócios sôbre os mesmos. realizados.

2 - A sua atuação no crédito a longo prazo é de suma relevância, pois facilitam a sua conversão, pràticamente, em crédito a prazo curto, uma vez que os mutuantes, ou tomadores dos títulos, encontram, no mecanismo bolsístico, grande facilidade em reduzir a numerário os títulos tomados, superando, assim, as dificuldades encontradiças na difusão do crédito a longo prazo, sôbre o que magistralmente discorre o Prof. EUGENIO GUDIN, em seus "Princípios de Economia Monetária" (Rio, 2. a edição, pag. 79).

E TÚLIO ASCARELLI: "É assim que, enquanto o problema dos títulos de crédito que chamaremos a longo prazo, se relaciona com o das bôlsas, os dos títulos de crédito a curto prazo se relaciona com o problema dos bancos de depósito". "Teoria Geral dos Títulos de Crédito", São Paulo, 1943, página 13, nota n. ${ }^{\circ}$ I).

Difere essencialmente, porém, a atuação dêsses institutos, pois enquanto os bancos operam diretamente, tomando e fornecendo cré- 
শito, a função das bôlsas é a do catalizador, facilitando e estimulando as operações. Aí, quem opera são terceiros, os compradores vendedores de títulos, por intermédio dos corretores e sob a disciplina bolsística.

Assim, pois, as Bôlsas de Valores estão intimamente ligadas com o problema de um dos fatôres da produção - o capital - mormente se considerarmos a formação, por subscrição pública, de sociedades por ações, coexistentes, em grande número, com o desenvolvimento industrial dos países mais adiantados do mundo. Ainda TÚLIO AS CARELLI, em conferência pronunciada na Associação Comercial de Pôrto Alegre, transcrita no "Boletim" de 31 de janeiro de 1945 páginas 35 a 47 , lembrou que "O problema da organização de um mercado de capitais diz respeito à organização e ao efetivo funcionamento de uma bôlsa de valores".

3 - O registro das operações, tanto na Secretaria da Bôlsa como nos livros legais do corretor, dão, às mesmas, grande segurança, em favor dos operadores, e, como exemplo, podemos citar o art. 340 do Código de Processo Civil que, aliás, no que tange à recuperação dos títulos ao portador, reproduz, mais precisamente, o conteúdo do parágrafo único do art. 521 do Cód. Civil.

4 - Decorrente da atuação a que podemos chamar centrîpeta - a de concentrar a oferta e a procura dos valores mobiliários ficam as Bôlsas em posição vantajosa no campo das pesquisas econômicas e financeiras, permitindo a extração de estatísticas e outras informações orientadoras, sendo, freqüentemente, apelidadas de "termômetros do crédito público".

5 - E' conhecido o relevante papel que, tanto na América como na Europa, têm desempenhado as Bôlsas de Valores. "Et la Bourse de Paris sut jouer son rôle dans cette oeuvre de développement économique de la France, en disciplinant les affaires, et en multipliant le crédit par des opérations au comptant et à terme. Badon-Pascal écrit à ce propos: “. . . c'est elle qui a fondé le credit de l'Etat, fait les chemins de fers, développé le commerce et l'industrie et subvenu aux travaux de la paix comme aux rançons de la guerre". " "In" ABELARDO VERGUEIRO CESAR, "La Bourse de Paris et son influence au Brésil”, São Paulo, 1946, página 15).

6 - Os males que alguns vêem nas Bôlsas não são do instituto, mas da detürpação de sua finalidade. Grande desvirtuamento desta é o chamado "jôgo de bôlsa”, malsinado, aliás, pelo art. 1479 do Cód. "Civil, que equipara ao jôgo os contratos sôbre títulos de bôlsa em "que se estipule a liquidação exclusivamente pela diferença entre o preço ajustado e a cotação que êles tiverem no vencimento do ajuste.

E' na detarpação do instituto que se fundam aquêles que ali- mentam preconceitos contra as Bôlsas. "Tinha razão THALLER em afirmar que as fantasias contadas a respeito das Bôlsas não revelam outra cousa que a ignorância da função que elas exercem - (Traité élémentaire de droit commercial, 5. ${ }^{\mathrm{a}}$ ed., n. ${ }^{\circ}$ 829)". As bôlsas são hoje indispensáveis, como a máquina a vapor, a eletricidade ou qualquer aparelho aperfeiçoado". (CARVALHO DE MENDONÇA, Tratado de Direito Comercial Brasileiro, vol. VI, 3. ${ }^{a}$ parte, n. $\left.{ }^{\circ} 1586\right)$.

No mesmo sentido - DESCARTES MAGALHÃES ("Direito Comercial", vol. I, 2. a edição, 1924, páginas 565 e segs., n. ${ }^{\circ} 44$ ); OCTAVIO MENDES ("Direito Comercial Terrestre", 1930, páginas 202 e segs.).

7 - Embora muito antiga a reunião de comerciantes para realizarem seus negócios, como o "Collegium Mercatorum", dos romanos, as Bôlsas de Valores, com a feição atual, tiveram seu desenvolvimento a partir do século dezesseis e cujo apogeu coincidiu com o surto industrial do século XIX. "La Bourse est donc une institution d'origine récente, puisque les valeurs mobilières n'ont vu le jour qu'à une époque relativement rapprochée et, surtout, qu'elles n'ont acquis leur plain développement q'au cours du XIX e (juntas aos algarismos romanos) siècle". (ALFRED COLLING, "La Prodigieuse Histoire de la Bourse", Paris, 1949, página 8).

8 - As Bôlsas de Valores são ếspécie do gênero Bôlsas de Comércio, que compreendem também as Bôlsas de Mercadorias (cereais, café, algodão, etc.) e outras. Sôbre as mesmas, porém, se destacam aquelas, em face da natureza do objeto de suas operações, dando lugar, em muitos países, a cuidadosa regulamentação. "Les Bourses de Valeurs Mobilières doivent être distinguées des autres bourses; en raison de l'importance des transactions dont les valeurs sont l'objet et de certaines particularités des opérations, ces bourses ont donné lieu à des règles spéciales". (A. WAHL, "Précis Théorique e Pratique de Droit Commercial", Paris, 1922, n. ${ }^{\circ} 1583$ ).

$$
- \text { II - }
$$

9 - Embora com a mesma função e finalidade, dividem-se as Bôlsas de Valores em dois tipos principais: - Bôlsas Livres, que são entidades de Direito Privado, e Bôlsas Oficiais, que são entidades de Direito Público. Num e noutro caso, porém, são coletividades de pessoas, ou corporações, para enquadrá-las na classificação adotada por FERRARA, em sua "Teoria de las Personas Juridicas". (Tradução da segunda edição italiana, Madrid, 1929). Compõem essas corporações os corretores que nelas labutam.

10 - No primeiro caso, temos, como padrão, as Bôlsas de Londres e de Nova York, que são associações civís, adotando, porém, re$29-$ R. D. $10^{\circ}$ Vol. 
gulamentação rigorosa na admissão dos membros componentes, com um número limitado de vagas, rigor que se verifica também na admisuão de valores à cotação.

No Uruguai e no Chile, as Bôlsas são entidades de Direito Privado. $\mathrm{O}$ mesmo acontecendo na Argentina, onde, entretanto, sofrem mais intenso contrôle estatal. "Según nuestro Código de Comércio se ha seguido el sistema de la Bolsa libre, pero con tales limitaciones, como vamos a verlo, que en definitiva el Estado busca garantir el interés social. Efectivamente: el Art. 76 establece que sólo pueden fundarse las Bolsas bajo cualesquiera de las formas de las sociedades mercantiles, inscribiendo y publicando sus documentos constitutivos", (ALBERTO CASSAGNE SERRES, "Bolsa de Comércio", Buenos Aires, 1921, pag. 15) "Estas razones han inducido a la comisión de letrados a dar a la Bolsa la forma de sociedad anónima, a fin de concordar con las prescripciones del Art. 76 del Código de Comercio e de reglamentar la actuación de los corredores que en las operaciones intervienen". (idem, idem). "Sólo corresponde dejar establecido, que entre la bolsa libre y la bolsa oficial, nuestra legislacion ha desechado la segunda; y que la tendencia hacia la intervención oficial en la constitución y funcionamento de las bolsas, no pone a nuestro país en el camino de abrazar el sistema de la bolsa oficial, sino de la bolsa fis-calizada en su constitución y funcionamiento, como sucede ya con las citadas disposiciones de la ley 12.253 , a la cual, em cualquer momento, podrían agregarse nuevas leyes fundadas en el interés general de la Nación". (MARIO RIVAROLA, “Tratado de Derecho Comercial Argentino", Buenos Aires, 1938, Tomo I, n. $\left.{ }^{\circ} 136\right)$.

Como vemos, nem sempre é própria a designação de Bôlsa Livre, para diferençá-la da Bôlsa Oficial. E' que esta, como entidade autárquica, poderá gozar, no seu funcionamento, de tanta liberdade quanto a primeira, mormente quando esta sofre fiscalização estatal intensa.

11 - Dò tipo Bôlsa Oficial temos como padrão a de Paris. Na Itália as Bôlsas também são do tipo oficial, criadas por decreto governamental, mediante proposta da Câmara de Comércio da respectiva praça. (G. DROUETS, "L'Organisarion \& le Fontionnement des Bourses de Valeurs en Italie", Paris, 1924, n. 15). Posteriormente, a competência para propor criação de Bôlsas passou para o "Consiglio dell'Economia". (LORENZO MOSSA, "Diritto Commerciale", Milão, 1937, 1. ${ }^{\circ}$ vol., pág. 47). Na Espanha, com a legislação posterior a 18 de julho de 1936, tôdas as Bôlsas devem ser oficiais, tendo, antes, existido concomitantemente os dois tpos, e cabendo às Câmaras de Comércio a faculdade privativa de fundar Bôlsas. (ANTONIO RODRIGUEZ SASTRE, “Operaciones de Bolsa”, Madrid, 1944, págs. 53 e segs.).
12 - No Brasil as Bôlsas são, também, do tipo oficial, tenda seguido, originàriamente, $\mathrm{o}$ modêlo francês. As leis do tempo do Imério, e referissem à Praça de Comércio, como o fêz o Código Comercial de 1850, não. mencionaram a palavra Bôlsa.

Em 16 de dezembro de 1895 , foi promulgada a lei federal n. ${ }^{\circ} 354$, reorganizando a corporação dos corretores de fundos públicos do Disreorganizando a corles realizadas trito Federal e providenciando sôbre as operações por êles realizadas na Bôlsa. Essa lei foi regulamentada pelo decreto federal n..$^{\circ} 2475$, de 13 de março de 1897. A cargo dos Estados federados ficou a criação 13 de março de 1897. A cargo dos mesmas normas estabelecidas para de outras Bôlsas, que adotaram as mesmas norman regulamentares. Em a do Distrito Federal, com ligeiras adaptaçóes regulamenta 13 de junho de 1939, o decreto-lei federal n. ${ }^{\circ}$ 1344, estendeu a todo o país princípios sôbre Bôlsa e operações bolsísticas, reconhecendo, o país princípios són a matéria (art. 50), tamporém, a vigência das leis estaduais sobre a matéria (art. bém declarando, nos têrmos do seu art. 59, em vigor o regulamento baixado com o decreto federal 2475, de 1897. Êsse decreto-lei 1344 alterou a denominação de Bôlsas de Fundos Públicos para Bôlsas de Valores, que é a correta e universalmente adotada.

Atualmente, existem Bôlsas de Valores nas seguintes cidades do Atualmente, existem Boiro, São Paulo, Santos, Pôrto Alegre, Recife Brasil: - Rio de Janeiro, Saro Pauliba. A de Pôrto Alegre foi criada pelo Bahia, Belo Horizonte decreto estadual n. $^{\circ} 484$, de 19 de agôsto de 1931.

13 - Criadas por ato do Estado, adquirem as Bôlsas autonomia administrativa, estando a administração de cada Bôlsa a cargo da respectiva Câmara Sindical, cujos membros são, anualmente, eleitos dentre os próprios corretores, por assembléia geral dêstes e mediante

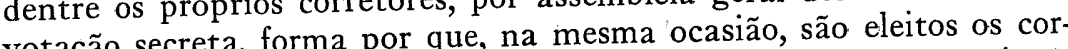
votação secreta, forma da Comissão de Contabilidade, que é o órgão interno de contrôle da economia da Corporação.

Cada Bôlsa tem o seu patrimônio próprio, formado principalmene resta e com os emote com as taxas remune corretores, mediante percentagens sôbre as comissões que percebem no exercício de sua profissão.

Uma vez criadas por ato do Estado, adquirem as Bôlsas o poder de elaborar e alterar os seus regimentos internos, que, entretanto, de após a respectiva aprovação pelo Ministro passam a vigorar ou pelo competente Secretário de Estado, respectivada Fazenda ou pelo compio de Janeiro ou dos Estados.

Dentro das normas dos seus regimentos internos são as próprias Bôlsas que nomeiam, pagam, etc., os seus funcionários; que elaboram os seus orcamentos e exercem todos os demais atos que atinam ram os seus orçalidade jurídica que possuem. A sua representação, em 
quaisquer atos judiciais ou extra-judiciais compete ao Síndico, que é o presidente da Câmara Sindical e eleito conjuntamente com esta.

14 - A ação do Estado sôbre as Bôlsas de Valores é das que caracterizam a entidade autárquica, pois podemos contar, entre os autores, quem se limite a apontar, como elementos extrínsecos das pessoas jurídicas dêsse gênero, a sua criação por ato do Estado e a ação tutelar exercida por êste sôbre a entidade criada. (TITO PRATES DA FONSECA, "Lições de Direito Administrativo, 1943, n. ${ }^{\circ}$ 51 ).

Já no ato da sua criação, o Estado traça-lhes diretrizes que devem ser observadas para a fiel consecução do fim a que se destinam, durante o seu funcionamento, a tutela se manifesta por diversos modos. Assim, é o Estado que nomeia os corretores, membros da corporação, após a habilitação dos mesmos perante a Câmara Sindical; os regimentos internos, elaborados pelas próprias Bôlsas, só éntram em vigor após a sua aprovação por ato do competente Secretário de Estado; para êste, cabe recurso das decisões da Câmara Sindical; é por decisão do mesmo que são admitidos à cotação, na Bôlsa, os títulos da dívida pública, tronando-se necessária, porém, no tocante aos títulos estaduais e municipais, a audiência prévia da Câmara Sindical.

15 - Não se deve confundir o estudo da estrutura e da natureza jurídica da Bôlsa, com as operações que ela centraliza e disciplina nem com a mediação exercida pelos corretores.

CARVALHO DE MENDONÇA, estudando, no seu clássico e magistral "Tratado de Direito Comercial Brasileiro", as operações de Bôlsa e a natureza jurídica da profissão do corretor de fundos públicos e particulares, não define a natureza jurídica das Bôlsas de Valores, reconhecendo, entretanto, que a matéria não pertence inteiramente ao plano dos Códigos Comerciais, mas também ao quadro do Direito Público. (Vol. VI, 3. ${ }^{\mathrm{a}}$ parte, n. ${ }^{\circ}$ 1584).

Em nosso país, portanto, como em todos aquêles que adotam o tipo "Bôlsa Oficial", as Bôlsas de Valores não se confundem com a sociedades comerciais. A sua natureza não pertence ao âmbito do $\mathrm{Di}$ reito Civil nem do Direito Comercial, mas do Direito Administrativo, São pessoas jurídicas de Direito Público e não de Direito Privado.

"Além da União e dos Estados e Municípios, ainda outras pes soas administrativas existem, entre as quais serviços públicos importantes são repartidos. Denominam-se essas pessoas administrativas entidades autárquicas, quer dizer, entidades que a si próprias se governam". (RUY CIRNE LIMA, "Princípios de Direito Administrativo Brasileiro", Pôrto Alegre, 1939, pág. 51). "São as entidades autárquicas pessoas de direito público" (Idem idem).

Essas pessoas jurídicas são criadas pelo Estado, em obediência ao princípio da divisão do trabalho, administrando, com maior conveniência, setores de suma importância e interêsse coletivo. Tratase de uma das formas da descentralização administrativa estatal, consistente na "distribuição de funções estatais a pessoas jurídicas "ad hoc" criadas pelo Estado, porém distintas dêste”. (Ob. cit. pág. 139).

16 - Vimos, assim, serem as Bôlsas Oficiais produtos da descentralização administrativa, com personalidade jurídica de direito público, ou sejam entidades autárquicas. Enquadrêmo-las, porém, mais especificamente.

Consultando as diversas obras de Direito Administrativo Brasileiro, encontrámos, nesse sentido, como classificação mais completa, jurídica e sistemática, a que, fundando-se, em princípio, na de FERRARA, divide as entidades autárquicas de conformidade com a respectiva estrutura interna, em três tipos fundamentais:

a) a CORPORAÇÃO, que é a personificação de uma coletividade de pessoas;

b) A FUNDAÇãO, que é a personificação de uma coletividade de bens;

c) o ESTABELECIMENTO PÚBLICO que "é o serviço público a que se reconhece personalidade jurídica".

Cada um dêsse tipos divide-se, por sua vez, em subtipos, de acôrdo com o seu objeto ou finalidade. (RUY CIRNE LIMA, ob. cit págs. 51 a 55 ).

Assim, as CORPORAÇÕES de direito público, como tipo estrutural de entidade autárquica, subdividem-se em vários subtipos, dos quais destacamos as Corporações de Disciplina Profissional, tendo como modêlo a Ordem dos Advogados do Brasil e cujos membros componentes são todos os advogados nela inscritos, e as corporações de. Disciplina Mercantil, que são as Bôlsas de Valores, cujos membros são os Corretores de Fundos Públicos e Particulares, nomeados para formarem os respectivos quadros. E a própria legislação reconhece a existência dessas Corporações, v. g., a lei federal 354 , de 1895 (ementa e art. $7 .^{\circ}$, letra b), bem como o decreto estadual n. ${ }^{\circ} 4847$, de 1931 (art. 70, n. ${ }^{\circ} 13$ ). Sua finalidade é como vimos, a disciplina do mercado dos valores mobiliários, com a intervenção dos corretores nas operações, estendendo, aos mesmos, a atividade disciplinar.

"As Bôlsas de Fundos Públicos são pessoas jurídicas, nascidas da descentralização; são corporações de disciplina mercantil (V. § 6 n. ${ }^{\circ} 3$, supra). Dos atos de suas Câmaras Sindicais, contudo, cabe recurso para o Govêrno Federal (no Distrito Federal), ou para o Govêrno Estadual (nos Estados). Tais recursos, a par de outras formas 
de contrôle, são manifestação do que se denomina a tutela administrativa do Estado". (RUY CIRNE LIMA, ob. cit., pág. 140).

A estrutura corporativa das Bôlsas é também reconhecida por autores estrangeiros, relativamente aos respectivos países. Assim, temos LORENZO MOSSA: - "La Borsa ha carattere corporativo, ha quindi una sua autonomia, che giunge ad ampi effeti". (Vol. cit., pág. 47).

Entretanto, existem ainda os que confundem as Bôlsas de Valores com as respectivas Câmaras Sindicais, tomando, impròpriamento, o órgão pela entidade; corruptela que, aliás, não é exclusividade dệsse setor, mas também encontradiça alhures, sendo vulgar, por exemplo, mencionar-se o Govêrno pelo Estado, a Prefeitura pelo Município, etc.

17 - Em face do exposto e adotando a classificação que consideramos a única jurídica, concluímos, em resumo, que, no Brasil, as Bôlsas de Valores são ENTIDADES AUTÁRQUICAS (federal a do Rio de Janeiro, e estaduais as outras) e, dentre os mencionados tipos e respectivas subdivisões, conceituam-se como CORPORAÇÕES DE DISCIPLINA MERCANTIL.

Pôrto Alegre, 10 de agôsto de 1950.

\section{RELATÓRIO E PARECÉR}

\section{Relator: HOMERO MARTINS BATISTA}

Por forma segura e ordenada, elaborou o Dr. José Baptista Neto a sua tese sôbre Bôlsas de Valores Mobiliários, assinalando a sua estrutura e natureza jurídica.

Conceitua-as, inicialmente, como mercados organizados que, pela concentração da oferta e da procura de títulos da dívida pública, e dos emitidos pelas sociedades por açôes, do câmbio e de outros valores mobiliários, bem como pela disciplina e registro das respetivas operações, facilitam a circulação dêsses valores, regulam as suas cotações e proporcionam segurança aos negócios sôbre os mesmos realizados. Nota-lhes o seu benéfico reflexo no crédito a longo prazo, ao ensejar a transformação dêste, pràticamente, em crédito a prazo curto, dada a facilidade que proporcionam essas BôLSAS na redução dos títulos em numerário, aspecto sob o qual se encontram intimamente ligadas com o problema de um dos fatôres da produção - o capital. Põe em relêvo a segurança decorrente do registro das operações na Secretaria da Bôlsa e nos livros legais dos corretores, com que favorece os operadores. Assinala o seu papel como "termômetro do crédito publico", como são apelidadas essas bôlsas, por possibilitarem, devido à concentração da oferta e procura dos valores mobiliários, a organização de estatísticas e informes orientadores das pesquisas econômicas e financeiras. Evidencia, enfim, o relevante papel que desempenham as BÔLSAS DE VALORES, fim, o releras as reservas que a elas opõem alguns autores, atribuinsem esquecer as resturpação das finalidades do instituto, exemplificando-as, todavia, à deturpação das finalidades do instituto, exemplino elas do com o chamado "jôgo de bôlsa". Seja, porem, con de Mendonça, hoje indispensáveis, como as consideram

Descartes Magalhães e Otávio Mendes.

Nota o autor, que as Bôlsas de Valores, com a feição atual, tiveram o seu desenvolvimento a partir do século XVI,

Filia as Bôlsas de Valores, como espécies, às Bôlsas do Comércio,

Filia as Bôlsas de que CAS IIVRES e BÔLSAS OFICIAIS, considerando-as entidades, BOLSAS LIVRe de direito privado e de direito público. Especifica respectivamente, de direito privado e sentando como padrões, do prios países onde são elas adotadas, apresentando como padrōes, do priParis.

Passa, então, ao estudo das Bôlsas, no Brasil, acentuando, de início serem do tipo oficial, e terem obedecido, originàriamente, o modêlo francês. Faz a resenha legislativa, de sua criação, depois de modêlo francês. a do Império, embora regulassem a profissão de correnotar que as leis do Imperio, embora regulassem a fêz o Código Comẹrcial se 1850 , não mencionam a palavra BôLSA. Destaca, como seu cial de 1850 , nto legal, a lei no 354 , de 16 de dezembro de 1895, que primeiro assento legal, aca dos corretores de fundos públicos do Distrito Federal providenciando sôbre as operações por êles realizadas na BOLSA e que foi regulamentada pelo decreto federal n. $^{\circ} 2475$, de 13 de marco de 1897. Conferida aos Estados federados a criação de outras BÔLSAS, teraim êles adotado as mesmas normas prescritas para o Distrito Federal, com ligeiras adaptações regulamentares. $O$ decreto-lei federal n. ${ }^{\circ} 1.344$, de 13 de junho de 1939 , estendeu a todo país os princípios sôbre BÔLSAS e suas operaçôes, reconhecendo, part os estaduais a respeito da matéria, sôbre contudo, a vigência das leis estado pelo decreto federal n. ${ }^{\mathrm{O}} 2.475$ maferido. E encerra êste escôrço, relacionando as cidades do Brasil, Teferdo. E EALORES, inclusive a de Pôrto Alegre, onde existem BOLSAS DE VALRES, tendo, a desta última, sido criada pelo decreto estadual n. ${ }^{\circ} 4.847$, de 19 de agôsto de 1931.

Passa, então, pròpriamente, à matéria da tese, estudando a estrutura e a natureza jurídica das BÔLSAS DE VALORES. Estuda, 
primeiro, assinalando a sua autonomia, a administração das BÒLSAS, a cargo da respectiva Câmara Sindical, constituída por membros eleitos anualmente, dentre os próprios corretores, em assembléia geral dêstes e mediante votação secreta, forma por que, na mesma ocasião, são eleitos os corretores que integram a Comissão de Contabilidade, órgão interno de contrôle da economia da Corporação. Investiga, a seguir, a formação do patrimônio das Bôlsas, caracterizando-o como próprio, de cada uma delas. Menciona a faculdade que a tôdas elas assiste, de eloborarem e alterarem os seus regimentos internos, sob a dependência, embora, da aprovação do Ministro da Fazenda, ou do Secretário de Estado a quem competir, em se tratando, respectivamente, de BôLSAS do Rio de Janeiro ou dos Estados. Salienta, depois, que são as próprias BÔLSAS, dentro das normas dos seus regimentos, que nomeiam, pagam, etc., os seus funcionários; que elaboram os seus orçamentos e exercem todos os demais atos que se relacionam com a pessoa jurídica que possuem, especialmente a sua representação em quaisquer atos judiciais ou extra-judiciais, exercida pelo Síndico, que é o presidente da Câmara Sindical, com a qual é eleito.

Examinando a ação do Estado em relação às BôLSAS de VALORES, aponta-a o autor, como daquelas que caracterizam a enti dade autárquica, pois como elementos extrínsecos das pessoas jurídicas dêsse gênero, bastam a sua criação por ato do Estado e a ação tutelar por êste exercida sôbre a entidade criada, conforme a lição de Tito Prates da Fonseca. (Direito Administrativo, 1943, n. ${ }^{\circ} 51$ ). Pormenoriza, então, os diversos modos pelos quais se manifesta essa tutela, sôbre assinalar que, já no ato de criação dessas entidades, traça-lhes o Estado diretrizes visando a fiel consecução dos fins que objetivam.

Previne o Autor, se não deve confundir o estudo da estrutura e da natureza jurídica da BÔLSA, com as operações que ela centraliza e disciplina, nem com a mediação exercida pelos corretores. E observa que, conquanto não houvesse Carvalho de Mendonça, em seu clássico e magistral Tratado, definido a natureza jurídica das BôLSAS, reconheceu, contudo, que a matéria não pertence inteiramente ao plano dos Códigos Comerciais, pois participa dos quadros do Direito Público. Inconfundiveis com as sociedades comerciais, as BÔLSAS DE VALORES, por sua natureza, refogem ao âmbito do Direito Comercial e ao do Direito Civil, incidindo na esfera do Direito Administrativo, constituindo pessoa jurídica de Direito Público e não de Direito Privado. Em prol desta assertiva, menciona o Autor ensinamentos hauridos nos "Princípios de Direito Administrativo Brasileiro" de Ruy Cirne Lima, segundo os quais "Além da União e dos. Estados e dos Municípios, ainda outras pessoas administrativas exis- tem, entre as quais serviços públicos importantes são repartidos. Denominam-se essas pessoas administrativas entidades autárquicas, quer dizer, entidades que a si próprias se governam. São as entidades. autárquicas pessoas de direito público". Trata-se de uma das formas. de descentralização administrativa, estatal, consistente na "distribuição de funções estatais a pessoas jurídicas "ad-hoc" criadas pelo Estado", na lição do mesmo autor.

Não satisfeito em demonstrar serem as BÔLSAS oficiais produtos da descentralização administrativa, com personalidade de DIREITO PÚBLICO, ou sejam entidades autárquicas, remata o Autor o seu trabalho, enquadrando-as ainda mais especificamente, como CORPORAÇÕES de DISCIPLINA MERCANTIL, ou seja em um dos subtipos em que se dividem as CORPORAÇÕES de Direito Público, com tipo estrutural de entidade autárquica, para concluir que, blico, com tipo estrutural de entidade autarquica, são ENTIDADES AUTÃROUICAS (federal, a do Rio de Janeiro, e estaduais as demais) e conQUICAS (federal, a do Rio de Jan TIL.

Como relator, não tenho dúvida alguma em adotar estas conclusões, como decorrência lógica das doutrinas e princípios legais expostos pelo Autor, sendo de parecer que a douta Comissão deva recomendá-la à aprovação plenária, do Congresso Jurídico.

Assim me pronuncio por ter como irrecusável que as BôLSAS de VALORES, oficiais, são entidades coletivas, titulares de direitos e obrigações, com autonomia administrativa e financeira, com jurisdição exclusiva, no tocante aos serviços a seu cargo, dentro das circunscrições territoriais que lhes são correspondentes. Sua administração incumbe à Câmara Sindical, eleita normalmente pela Assembléia dos Corretores, e responsável, através de seus membros, pelas faltas e erros cometidos nas atividades que lhe são peculiares. Tem patrimônio próprio, enfeixado na Caixa de Garantia e Previdência. Dentre as múltiplas atribuições do Síndico, sobrelevam às demais, a representação das Bôlsas e da Caixa, em juízo e fora dêste, e a mantença de relações com as Bôlsas e instituições comerciais estrangeiras. Para a consecução de seus fins, acham-se as BôLSAS investidas. de atribuições e poderes de ordem pública, que lhes conferem a exclusividade do exercício, por intermédio dos seus corretores, seus. membros, da compra e venda e transferência de quaisquer títulos ou fundos públicos e particulares admitidos à negociação e cotação na BôLSA; a negociação de letras de câmbio e empréstimos por meio de debêntures, etc. Têm, assim, direitos e obrigações próprias, não se lhes podendo, portanto, recusar a personalidade. Conquanto não estejam enumeradas entre as pessoas de direito público interno, arroladas pelo art. 14 do Código Civil, também não é possível se lhes ne- 
gar êsse caráter, instituídas que são pelo próprio Estado, como emanação de seu poder. São estabelecimentos públicos autônomos, ou autarquias atuando em lugar do Estado, no sentido de interêsses revestidos de caráter público, valendo a sua vontade como a vontade do Estado, de que são criações. De resto, a sua constituição corporativa, e a natureza das atividades públicas a seu cargo, justificam a sua classificação entre as CORPORAÇÕES DE DIREITO PÚBLICO, como CORPORAÇÕES de DISCIPLINA MERCANTIL.

Pôrto Alegre, 15 de agôsto de 1950.

\author{
Homero Martins Baptista - Relator \\ Antônio Martins Filho
}

\section{DEBATES EM PLENÁRIO:}

O SR. PRESIDENTE - José Salgado Martins - Vamos passar ao relatório da tese "Bôlsas de Valores Mobiliários - Estatuto e Natureza Jurídica", de autoria do senhor José Batista Neto. E' relator o senhor desembargador Homero Martins Batista, a quem concedo a palavra.

O SR. HOMERO BATISTA - Sr. Presidente, srs. Congressistas.

Tenho a honra de dar conhecimento a esta douta assembléia, do relatório e do parecer por mim elaborados em relação à tese apresentada pelo distinto colega José Batista Neto, sôbre bôlsas de valores mobiliários - estrutura e natureza jurídica.

\section{(LE O RELATÓRIO E O PARECER)}

Este parecer foi aprovado por unanimidade pela Comissão, tendo ‘o ilustre professor Bonazzola ressalvado no tocante ao Direito Comercial Comparado, por isso que, na Argentina, as Bôlsas de Valores não são oficiais: são pessoas de Direito Privado. (Palmas).

O SR. PRESIDENTE - Está em discussão o parecer. Não havendo quem queira discutí-lo, vou pôr em votação. Os senhores que o aprovam queiram ficar sentados. (Pausa) Aprovado.

\section{AVERIA COMUN}

\section{SU CARACTERIZACION MEDIANTE EL ESTUDIO COMPARATIVO DEL CODIGO Y DE LAS REGLAS DE YORK Y AMBERES 1924 (*)}

\section{SIVORI e J. C. BONAZZOLA}

Catedráticos de la Facultad de Derecho y Ciencias Sociales de Buenos Ayres.

Para caracterizar mediante el estudio comparativo de las disposiciones del Código y las Reglas de York - Amberes debo señalar la filiación de los textos que han de servirme para inducir las conclusiones encomendadas. $\mathrm{Y}$ por ser el tema concreto entro a examinarlo, atendiendo el afán de ceñirme a él.

Nuestro Código habla de avería en muchas de sus disposiciones del Libro III, y con conceptos distintos, no descartando ni el vulgar: el de mercadería averiada por dificencias proprias de la mismo: ejemplo, en el artículo 913, pero siempre con un criterio jurídico preciso. En el artículo 1316 cuyas fuentes directas son el artículo 1816 del Código Portugués y el art. 976 del Código Español, el que más interesa en esta oportunidad. El texto del art. 1316 lo reproduce el art. 1476 del Proyecto de los Doctores Dalmacio Vélez Sarsfield y Eduardo Acevedo, preparado por éste y revisado por aquél, sin que

de (*) "A ${ }^{*} O$ O DEL LIBERTADOR GENERAL SAN MARTIN", Buenos Aires, 20 Al Julmo. y Excmo. Señor Decano de la Facultad de Derecho de Pôrto Alegre. Uni. versidade do Rio Grande do Sul, Pôrto Alegre (Brasil). Ciências Jurídicas de Buenos Aires, para concurrir al Congreso Jurídico que se realizará bajo el auspicio de esa Facultad en el próximo mes de agosto, tienen el honor ponencia $\mathrm{y}$ antecedentes que expresan a continuación. Los países de Latino América cumplen una honrosa trayectoria de tradición ju. rídica $\mathrm{y}$ son exponentes de una insuperable legislación político constitucional. El Co digo de Comerclo de Brasil despunta su entenaro el de la República Argentina que Presidente de La Confederación General Bertolomés J Mitre, y obra de Vélez Sarsfield, en colaboración con Acevedo dan pruebas del sentido monitor que tuvieran en su

Obras ambas de un esfuerzo digno de encomio, como las del resto de Sudamérica,
Obró 